\title{
A comparison of methods for determining the partition coefficient of gadolinium in the myocardium using T1 mapping
}

\author{
Rajesh Janardhanan*, Ronny S Jiji, Jeremy Brooks, Frederick H Epstein, Christopher M Kramer, Michael Salerno
}

From 2011 SCMR/Euro CMR Joint Scientific Sessions

Nice, France. 3-6 February 2011

\section{Introduction}

Late gadolinium enhancement can evaluate focal, but not diffuse myocardial fibrosis. T1-mapping techniques can quantify fibrosis by calculating the partition coefficient $(\lambda)$ of gadolinium $(\mathrm{Gd})$. One method (CI) calculates $\lambda$ at equilibrium following a continuous infusion of $\mathrm{Gd}$, while the other, early post-contrast method (EPC), determines $\lambda$ from multiple post-contrast time points after Gd injection. The Modified Look-Locker Inversion Recovery (MOLLI) technique accurately performs T1 mapping, but may be limited in practice due to the long breathhold required. A shortened-MOLLI technique (Sh-MOLLI) has been described, which only allows a single heart beat for magnetization recovery.

\section{Objectives}

To (i) compare $\mathrm{T} 1$ values determined with reduced breathhold MOLLI schemes to the standard MOLLI technique, and (ii) to directly compare $\lambda$ determined by the CI and EPC methods.

\section{Methods}

T1 mapping was performed in 10 healthy volunteers (age $34 \pm 11$ ) on a Siemens $1.5 \mathrm{~T}$ Avanto using 3 MOLLI schemes: (i) Standard MOLLI (ii) 3-5 MOLLI (11 heart beats, 2 inversions, 3 recovery beats, 8 images), (iii) 2-24. MOLLI (12 heart beats, 3 inversions, 2 recovery beats, 8 images). Sequence Parameters included: TE/TR/FA 1.1 $\mathrm{ms} / 2.5 \mathrm{~ms} / 35^{\circ}, \mathrm{FOV}=340 \times 260$, resolution $1.8 \mathrm{~mm} \times$ $1.8 \mathrm{~mm}$, thickness $8 \mathrm{~mm}$. T1 was determined pre-contrast and every 5 minutes following injection of $0.1 \mathrm{mmol} / \mathrm{kg}$ Gd-DTPA. At 15 minutes a continuous infusion of $0.001 \mathrm{mmol} / \mathrm{kg} \mathrm{Gd}$ was administered until equilibrium was achieved. $\lambda$ was determined using the CI and EPC methods. T1 maps were calculated and manually segmented using an in-house MATLAB program.

\section{Results}

The standard MOLLI and the 3-5 MOLLI sequences provided comparable $\mathrm{T} 1$ values for myocardium and blood both pre- and post-contrast, whereas the 2-2-4

Table 1 Mean T1 values and partition co-efficients observed

\begin{tabular}{|c|c|c|c|c|}
\hline Mean Values & Standard MOLLI & 3-5 MOLLI & 2-2-4 MOLLI & P-value \\
\hline T1 of blood pre-contrast (msec) & $1478 \pm 86$ & $1480 \pm 100$ & $1390 \pm 91$ & 0.06 \\
\hline T1 of myocardium pre-contrast (msec) & $972 \pm 27$ & $953 \pm 38$ & $919 \pm 84$ & 0.11 \\
\hline T1 of blood post-contrast (msec) & $488 \pm 36$ & $487 \pm 43$ & $484 \pm 44$ & 0.97 \\
\hline T1 of myocardium post-contrast (msec) & $601 \pm 37$ & $597 \pm 37$ & $600 \pm 30$ & 0.96 \\
\hline Partition Co-efficients (Cl-based method) & $0.47 \pm 0.04$ & $0.45 \pm 0.05$ & $0.45 \pm 0.03$ & 0.39 \\
\hline Partition Co-efficients (EPC-based method) & $0.49 \pm 0.05$ & $0.47 \pm 0.05$ & $0.45 \pm 0.04$ & 0.20 \\
\hline
\end{tabular}

University of Virginia, Charlottesville, VA, USA

(c) 2011 Janardhanan et al; licensee BioMed Central Ltd. This is an open access article distributed under the terms of the Creative 


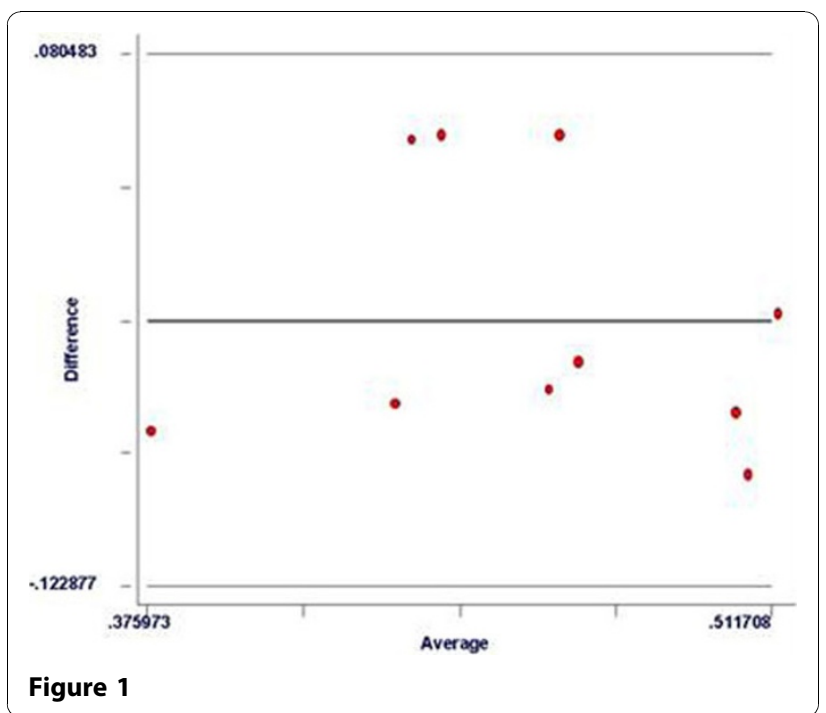

MOLLI sequence had a bias towards lower T1 values pre-contrast (see table 1). There was good agreement between the partition co-efficient of gadolinium for the CI method and for the EPC method (see Figure 1).

\section{Conclusions}

The 3-5 MOLLI sequence produces reliable T1 maps in a short clinically-applicable breathhold and is comparable to the standard approach. The 2-2-4 MOLLI sequence had a bias towards lower T1 values precontrast, possibly due to insufficient $\mathrm{T} 1$ relaxation between inversion pulses. The $\lambda$ obtained by either the CI or EPC methods were similar. Using the EPC method, T1 mapping can quantify diffuse myocardial fibrosis without requiring a long equilibrium phase.

Published: 2 February 2011

doi:10.1186/1532-429X-13-S1-081

Cite this article as: Janardhanan et al: A comparison of methods for determining the partition coefficient of gadolinium in the myocardium using T1 mapping. Journal of Cardiovascular Magnetic Resonance 201113 (Suppl 1):081.
Submit your next manuscript to BioMed Central and take full advantage of:

- Convenient online submission

- Thorough peer review

- No space constraints or color figure charges

- Immediate publication on acceptance

- Inclusion in PubMed, CAS, Scopus and Google Scholar

- Research which is freely available for redistribution

Submit your manuscript at www.biomedcentral.com/submit 